\title{
Dynamic Response of Air Cushion Vehicle's Skirt under High Pressure Bubble Impact
}

\author{
Ching-Yu Hsu ${ }^{\mathrm{a}}$, Cho-Chung Liang ${ }^{\mathrm{b}}$, Phuong-Duy Vo ${ }^{\mathrm{b}}$, Hai-Anh Nguyen ${ }^{\mathrm{c}}$
}

\begin{abstract}
Skirt is a part of air cushion vehicle (ACV) which plays a substantial role to create an over-pressure (above atmospheric pressure) between floor of structure and water surface. This pressure lifts main hull structure in order to travel through different surfaces as sea-surface, mud, and land. A suitable materials of ACV's skirt is necessary to survive ACV before high-pressure bubble in under-water explosion (UNDEX). This paper builds up a technique which connects together the finite element method (FEM) and Coupled Eulerian- Langrangian (CEL) strategy to simulate and modify predicted data whereas the high-pressure bubble impact air cushion vehicle (ACV). To prove the promising results of this technique, authors conducted two feature studies from Klaseboer et al. (2005) [1] and A. M. Zhang again in Abaqus software [2], which showed the precision of the calculation model and method. With the similar above model, finite element simulation of the ACV's skirt model subjected to high-pressure bubble impact that were presented, and discussed the skirt response of the hovercraft model. The consequences of numerical methodology could be as an important reference to outline ACV's skirt structure.
\end{abstract}

Keywords- underwater explosion, high-pressure bubble, ACV's skirt design, hovercraft design.

\section{Introduction}

Air Cushion Vehicle (ACV) is equipped for moving over land, water, mud, ice, and different surfaces. Sir Christopher Cockerell's experiment in England alluded to this idea in the prior period and was begun from 1955 [3].

Ching-Yu Hsu ${ }^{a}$

${ }^{a}$ Department of Marine Mechanical Engineering, ROC Naval Academy.

Taiwan, ROC

Cho-Chung Liang ${ }^{\mathrm{b}}$, Phuong-Duy Vo ${ }^{\mathrm{b}}$

${ }^{b}$ Department of Mechanical and Automation Engineering, DaYeh University,

Taiwan, ROC

Hai-Anh Nguyen

${ }^{c}$ Department of Mechanical Engineering, National Chiao Tung University,

Taiwan, ROC
In this paper, high-pressure gaseous bubble will be attended as a main factor to cause the interaction from UNDEX. Following this major field of study's history, Rayleigh made the first analysis of a problem in cavitation and bubble dynamics (1917), he solved the problem of the collapse of an empty cavity in a large mass of liquid[4]. More recently the same type of problem has been considered in greater detail by several investigators including Devin (1959), Plesset \& Hsieh(1960), Chapman\& Plesset (1971), and Prosperetti (1976) [4]. The particular attention to the interaction between structure and bubble oscillation in underwater explosion nearby a wall by finite volume method was presented by H. Q. Zhang (2015) [5]. A threedimensional model of collapsing bubble with jet formation and impact is presented in the Y. L. Zhang's study (2000). The main contents are the strong instabilities of the jetting process, impact, toroidal bubble rebound, and a smooth transition from a singly connected bubble to a doubly connected toroidal bubble [6]. Another attention to the much smaller-scale cavitation bubbles and associated theoretical and computational studies was conducted by A.Pearson (2001). The cubic splines are used to represent the surface of the bubble and the infinite free surface; with a nonlinear distribution of nodes being employed on the free surface when bubbles are generated close to the boundary [7]. A high order of mesh regularity is maintained by a mesh refinement procedure. The circulation of the flow around the gaseous tube of the toroidal bubble is modelled by a generalization of the vortex ring method of Q. X. Wang (1995) [8]. The proposed elastic mesh technique (EMT) based on the segments was showed by C. Wang (2002). EMT employed in conjunction with the boundary integral method (BIM) for the simulation of three-dimension bubble dynamics in which problems relating to severe mesh distortion as the bubble evolves are a common occurrence (C. Wang, 2002) [9]. Majority of extant literature mainly focuses on underwater explosion bubbles and their 
Proc. of the Seventh International Conference On Advances in Civil and Structural Engineering - CSE 2017. Copyright (C) Institute of Research Engineers and Doctors. All rights reserved.

ISBN: 978-1-63248-127-6 doi: 10.15224/ 978-1-63248-127-6-36

interactions with a free surface. The volumeacceleration model was introduced to determine the initial conditions for bubble motion during underwater explosions that the initial and boundary conditions of the fluid field, were developed based on the MSC.DYTRAN software were used by Jian Li (2011) [10]. The interaction between a bubble and a free surface as basis, the simulation the dynamic behavior of a bubble near a free surface, including the ring rebound of the bubble and the spray dome of the free surface were illustrated [11]. The application of finite element program for solving UNDEX bubble problem has been addressed by Ching-Yu Hsu (2014). This study used the Eulerian technique in ABAQUS to simulate the first oscillation cycle of a 3-D UNDEX bubble in a free field. The availability of many materials in this technique allowed the simultaneous simulation of three materials, explosive gas product, air, and water, in the same Eulerian domain [12]. The numerical methodology to model and study the bubble dynamics produced by an underwater explosion when it occurs in infinite medium with any surrounding obstacle as the free surface, the seabed or deformable structures (surface ship or submarine) were indicated by G. Barras (2012) [13]. The Euler-Lagrangian approaches were also developed in the 1980s. Johansen and Boysan published an axisymmetric model for bubble plumes in reactors. It has been argued that in full 3D and for relevant gas release rates, Lagrangian tracking of the resulting number of bubbles is very demanding on computer resources, and thus an Eulerian-Eulerian approach is preferable for bubble plumes with a huge quantity of bubbles. Jan Erik Olsen (2016) applied an EulerianLagrangian CFD model to imitate the underwater bubble plumes emerge from subsea releases of gas. It accounts for relevant physics including buoyancy, turbulence, gas expansion and dissolution [14].

The behavior of an oscillating bubble near a floating structure was described by E. Klaseboer (2005) using the boundary integral method. The proposed modification of the BIM method was used to visualize the dynamics of (large) bubbles near a free surface and a (fixed) floating structure are investigated [1]. This procedure will be reproduced in Abaqus application. The results comparison of the consequence between two methods is a proof of accuracy. The air cushion vehicle $(\mathrm{ACV})$ is the advanced marine vehicle that provides not only excellent performance on rough surfaces but also the high speed that other conventional marine vehicles could not achieve. Hence, a large number of ACVs have been utilized for various purposes and missions. The flexible skirt system is recognized as the most updated and advanced skirt system. The ACV's skirt system geometry is optimized to modify an undesirable heave response for the better ride quality by using the Genetic Algorithm (GA) (Joon Chung, 2004) [3]. In the aforementioned literature the UNDEX response was primarily studied for ships and submerged structures; however, no studies exist on dynamic responses of an air cushion vehicle's skirt. For that reason, applying an UNDEX situation to ACV's skirt is the main issue of this research.

\section{Theoretical background}

In this paper, the response of a hovercraft Russian Zubr-class (Project 1232.2, Pomornik, Weight: 555 tons -full load; Length: $56.2 \mathrm{~m}$; Beam: 25.5 m; Draught: 1.6m; Speed: 60 knots [110 Km/hr]; Range: 300 miles [480 Km]; Crew: 31) [15] is the main concern within. The results of simulation can predict and choose an appropriated material of skirt to design a future ACV. The chemical reaction produces gases at very high temperatures and pressures. The internal energy of the gas at this time is small and is less than half of the maximum radius that it will eventually reach. At this low pressure, it is reasonable to apply the incompressible flow equations to determine the behavior [16]. The empirical equation of maximum bubble radius $\left(A_{\max }\right)$ and the time of the first pulse $(T)[16]$ :

$$
\begin{aligned}
& T=K_{5} \frac{W^{1 / 3}}{(D+9.8)^{5 / 6}} \\
& A_{\max }=K_{6} \frac{W^{1 / 3}}{(D+9.8)^{1 / 3}}
\end{aligned}
$$

where K5, K6 are constants depending on explosive charge type; D is the depth of the explosive in meters. For the numerical simulation of the interaction between a high-pressure bubble phenomenon and structure, the acoustic structural coupling method from the ABAQUS software was applied[17]. Eulerian material can interact with Lagrangian elements through EulerianLagrangian contact; simulations that include this type of contact are often referred to as coupled Eulerian-Lagrangian (CEL) analyzes. This powerful, easy-to-use feature of Abaqus/Explicit general contact enables fully coupled multiphysics simulation such as fluid-structure interaction [17-18].

\section{Validation of the simulation}




\section{A. Simulation of bubble and free dynamics in underwater explosion}

To validate calculation model, the interaction between a bubble and a free surface, the comparison is to be made between numerical results and the experimental results obtained by Klaseboer et al. (2005)[1]. Hexocire (55g) was placed at a depth of $3.5 \mathrm{~m}$. The pond sidewalls were designed to diffract the shock waves induced by the explosion and absorb the bulk of the explosion energy. This numerical simulation focused on the dynamic process of bubbles in a free field, especially the bubble collapse phase. The numerical analysis was conducted using an Eulerian-based finite volume program. The entire Eulerian domain includes three regions of material as water, air, and highly compressed detonation gas as Figure.1.

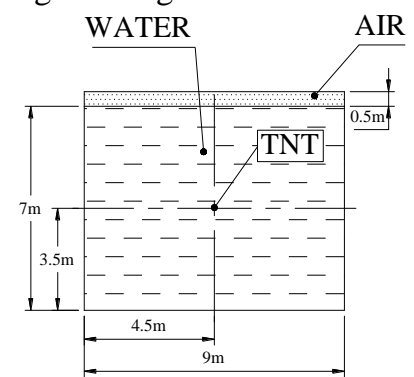

Figure 2. Set-up numerical model

The air domain and explosive gas were modeled using ideal gas Equation of State (EOS), whereas the water domain was model using the $U_{P}-U_{S}$ EOS. The physical parameter details of the numerical model were presented on the Table 1.

All faces of the Eulerian domain were fixed to prevent materials flowing out, and a nonreflecting Eulerian boundary was used for the side boundaries of the Eulerian domain to eliminate the reflection of pressure waves that may affect the simulation result accuracy. To obtain accurate results and conserve computational resources, the initial bubble region was meshed at the small size of $5 \mathrm{~mm}$. The region of $700 \mathrm{~mm}$ from the bubble center had a mesh size of $20 \mathrm{~mm}$, and the remaining model region had a large mesh size. Figure.2 and TABLE 1 shows half of the model and an enlarged view of the mesh surrounding the original bubble.

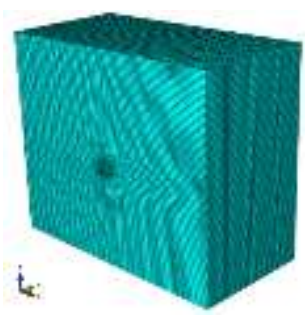

Figure 3. Mesh solution of the numerical model The overall model element mesh consisted of 1,173,872 EC3D8R elements.

If the charge is a sphere, then the charge radius is calculated using

$$
r_{c h}=\left(\frac{3}{4} \frac{W}{\pi \rho_{0}}\right)^{\frac{1}{3}}
$$

Where $W$ is the charge weight, and $\rho_{0}$ is the charge density. Based on the calculations by Cole [19], the relationship between pressure and specific volume is shown in Figure.3.

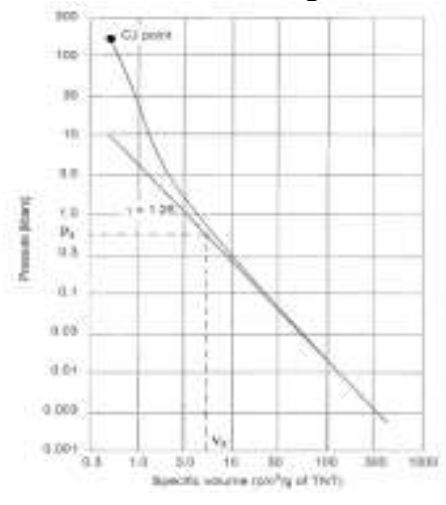

Figure 3. Cole calculation for TNT on the logarithmic plot [19]

The heat exchange between the detonation gas product and the water domain can be negligible in studying the UNDEX bubble, the expansion and contraction of detonation gas are considered to be an adiabatic process. Thus, the ideal gas EOS in ABAQUS is applicable for simulating the properties of air and detonation gas. The water domain in the numerical model was simulated using $U_{P^{-}} U_{S}$ EOS in ABAQUS. On the TABLE 1, the details of physical parameters are showed.

TABLE 1. Physical Parameters of Numerical Model

\begin{tabular}{|c|l|c|c|c|}
\hline Material & Parameter & Symbol & Value & Unit \\
\hline \multirow{3}{*}{ Water } & Density & $\rho_{w}$ & 1000 & $\mathrm{~kg} / \mathrm{m}^{3}$ \\
\cline { 2 - 5 } & $\begin{array}{l}\text { Sound } \\
\text { speed }\end{array}$ & $C_{w}$ & 1500 & $\mathrm{~m} / \mathrm{s}$ \\
\hline \multirow{6}{*}{ Air } & Density & $\rho_{a}$ & 1.17 & $\mathrm{~kg} / \mathrm{m}^{3}$ \\
\cline { 2 - 5 } & $\begin{array}{l}\text { Ratio of } \\
\text { specific } \\
\text { heat }\end{array}$ & $\gamma_{a}$ & 1.4 & - \\
\cline { 2 - 5 } & $\begin{array}{l}\text { Initial } \\
\text { pressure }\end{array}$ & $P_{a}$ & $1.0 \times 10^{5}$ & $\mathrm{~Pa}$ \\
\hline
\end{tabular}


Proc. of the Seventh International Conference On Advances in Civil and Structural Engineering - CSE 2017. Copyright (C) Institute of Research Engineers and Doctors. All rights reserved.

ISBN: 978-1-63248-127-6 doi: 10.15224/ 978-1-63248-127-6-36

\begin{tabular}{|c|l|c|c|c|}
\hline \multirow{2}{*}{$\begin{array}{c}\text { Explosive } \\
\text { (TNT) }\end{array}$} & Weight & $W$ & 0.055 & $\mathrm{~kg}$ \\
\cline { 2 - 5 } & Density & $\rho_{c h}$ & 1630 & $\mathrm{~kg} / \mathrm{m}^{3}$ \\
\cline { 2 - 5 } & $\begin{array}{l}\text { Charge } \\
\text { radius }\end{array}$ & $r_{c h}$ & 0.02 & $\mathrm{~m}$ \\
\hline \multirow{4}{*}{$\begin{array}{c}\text { Gas } \\
\text { Bubble }\end{array}$} & Density & $\rho_{g}$ & 203.75 & $\mathrm{~kg} / \mathrm{m}^{3}$ \\
\cline { 2 - 5 } & $\begin{array}{l}\text { Ratio of } \\
\text { specific } \\
\text { heat }\end{array}$ & - & 1.25 & - \\
\cline { 2 - 5 } & $\begin{array}{l}\text { Bubble } \\
\text { radius }\end{array}$ & $r_{g}$ & 0.04 & $\mathrm{~m}$ \\
\cline { 2 - 5 } & $\begin{array}{l}\text { Initial } \\
\text { pressure }\end{array}$ & $P_{g}$ & $5.672 \times 10^{7}$ & $\mathrm{~Pa}$ \\
\hline
\end{tabular}

B. Comparison the results between live experiment and simulating

Simulated and experimental bubbles show similar bubble radials at different intervals as TABLE 2 .

TABLE 2. The Comparison of Experimental and Optimal Bubble with similar Radials at Different Time

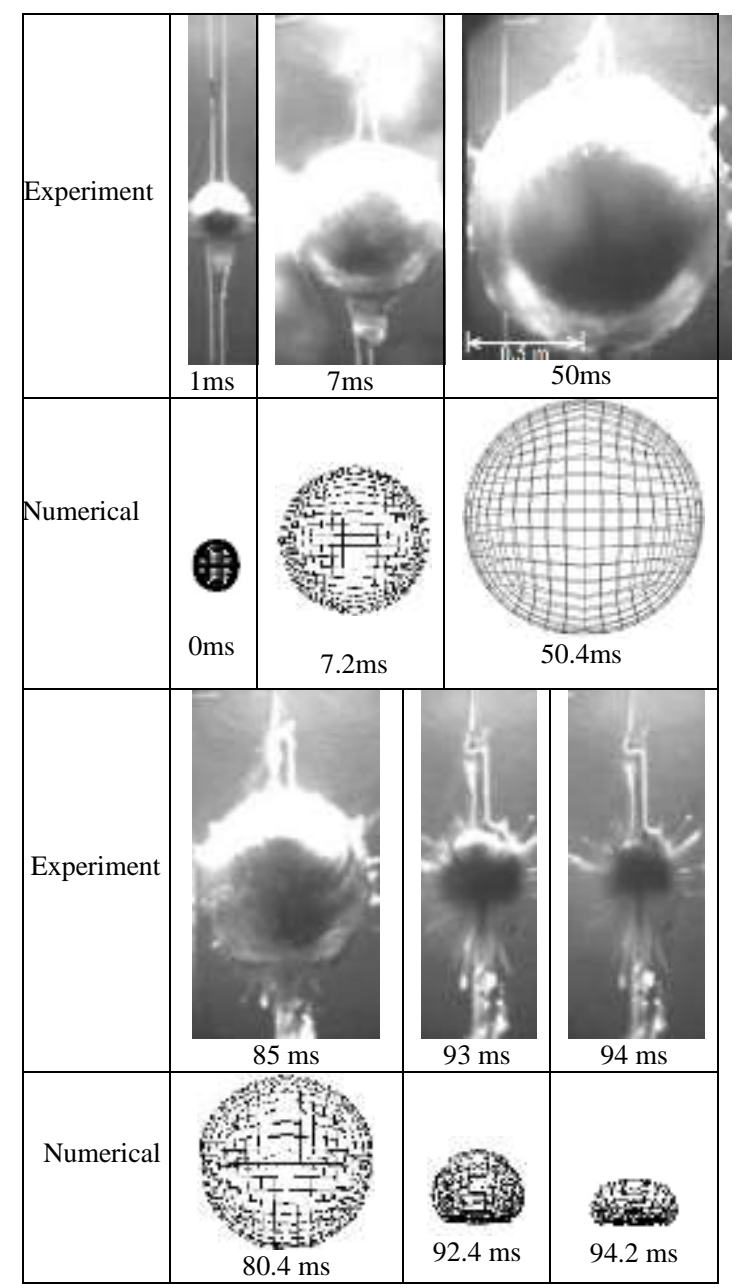

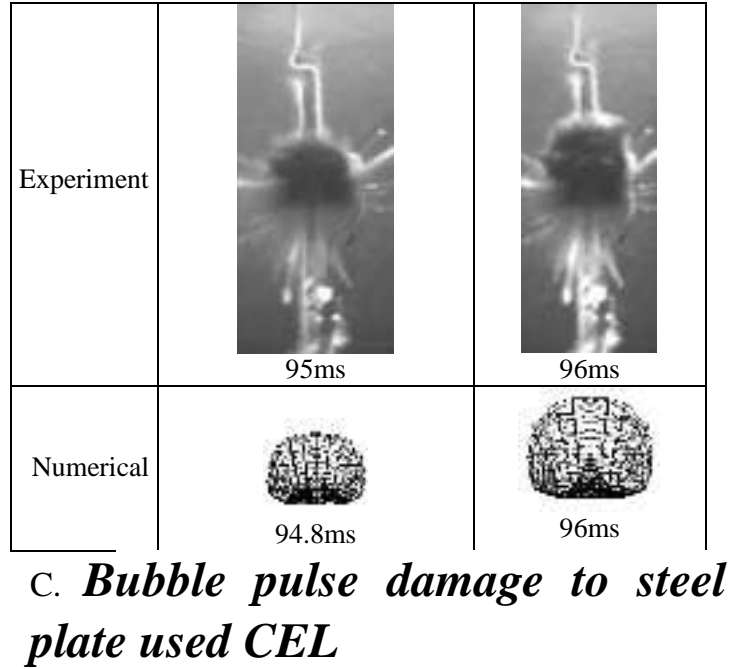

The CEL technique embedded in the ABAQUS is applied for solving the interaction between the fluid and the structures. In this section, we apply the CEL method to the numerical study of the bubble pulse impact to a rectangular plate (the same model in section III, had dimensions of $0.3 \times 0.25 \times 0.002 \mathrm{~m})$ subjected to UNDEX. This numerical simulation focused on the examining the behavior of a rectangular plate. The interaction between a high-pressure bubble and an elastic-plastic round plate is examined in this area; the experimental data are from reference [2]. The test was completed in a pool: an explosive charge of $55 \mathrm{~g}$ detonated under the roundabout steel plate of thickness $2 \mathrm{~mm}$. The steel plate was settled at first glance, one side experienced the impacting load and the opposite side was exposed in the air. The mass density of the plate is $7800 \mathrm{~kg} / \mathrm{m}^{3}$; the yield stress is $240 \mathrm{MPa}$; the shear modulus is $80.7 \mathrm{GPa}$ while the Young's modulus is $210 \mathrm{GPa}$; and the Poisson's proportion is 0.3. Expected the model was perfect elasticplastic and the dimensionless damping proportion was taken as 0.05. The steel plate had been settled at its boundaries for each of the six degrees of freedom and it was sufficiently thick to permit moderately extensive large deformation of the plate to happen. The standoff separate had been $1.2 \mathrm{~m}$ underneath the plate (or 2.2 times of the most extreme air bubble span). The separation between the explosive charge and the floor of the lake was $3.5 \mathrm{~m}$ (the charge depth was likewise $3.5 \mathrm{~m}$ ). The diagram of Finite Element (FE)

dama

4. $\mathrm{Si}$

than

some Explosive charge nume

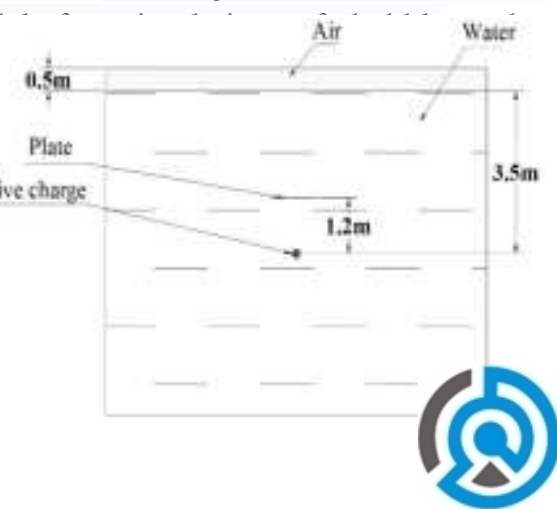


Proc. of the Seventh International Conference On Advances in Civil and Structural Engineering - CSE 2017. Copyright $\odot$ Institute of Research Engineers and Doctors. All rights reserved.

ISBN: 978-1-63248-127-6 doi: 10.15224/ 978-1-63248-127-6-36

the vertical removal of the plate is appeared in Figure.6.

Figure 4. Schematic diagram of FE model for simulation of bubble pulse damage to steel plate used CEL

The numerical analysis was conducted using an Eulerian based finite volume program. The entire Eulerian domain includes three regions of materials: water, air, and highly compressed detonation gas. The air domain and explosive gas were modeled using ideal gas EOS, whereas the water domain was model using the $U_{P^{-}} U_{S}$ EOS.

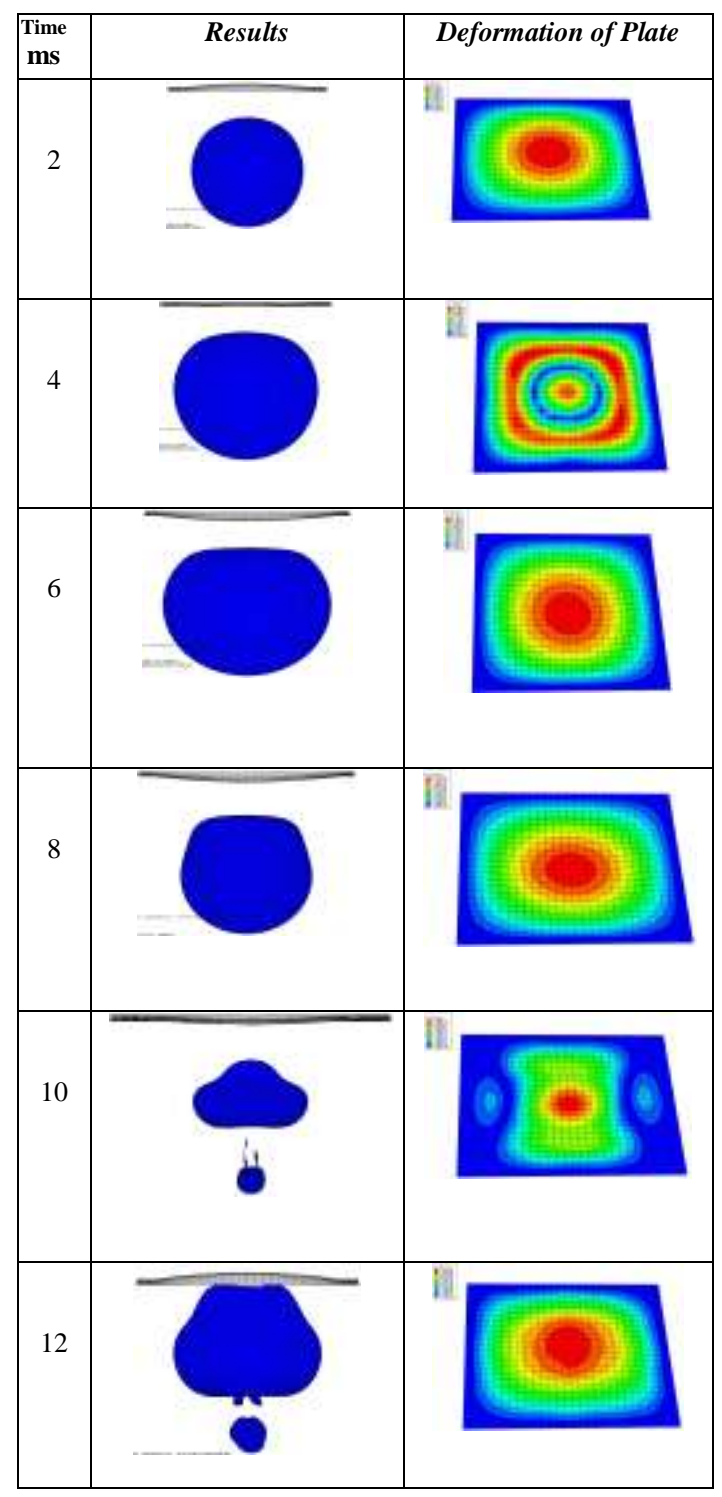

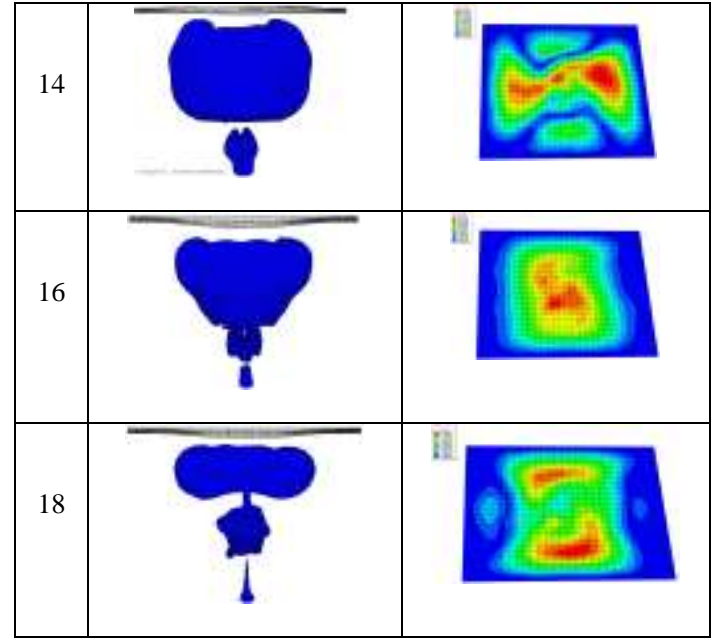

Figure 5. The shape of bubble and steel plate at different time

TABLE 1 shows the physical parameter details of the numerical model. All faces of the Eulerian domain were fixed to prevent materials flowing out, and a non-reflecting Eulerian boundary was used for the side boundaries of the Eulerian domain to eliminate the reflection of pressure waves that may affect the simulation result accuracy. The overall model meshes in EC3D8R element type. The present research focused on studying the influence of the deformation of steel plate on the behavior of bubble. Figure. 5 has shown the deformation of the steel plate at different time intervals; deformation was caused by the motion of the flow surrounding the bubble. The effect of the attraction between the bubble and the wall on the deformation of the wall was not clear. Permanent deformation at the center point of steel plate is plotted in Figure 6. There were wild fluctuations in the deformation around $0.02 \mathrm{~m}$ over $0.02 \mathrm{~s}$ before a sudden reaching the highest position with deformation is $0.1 \mathrm{~m}$.

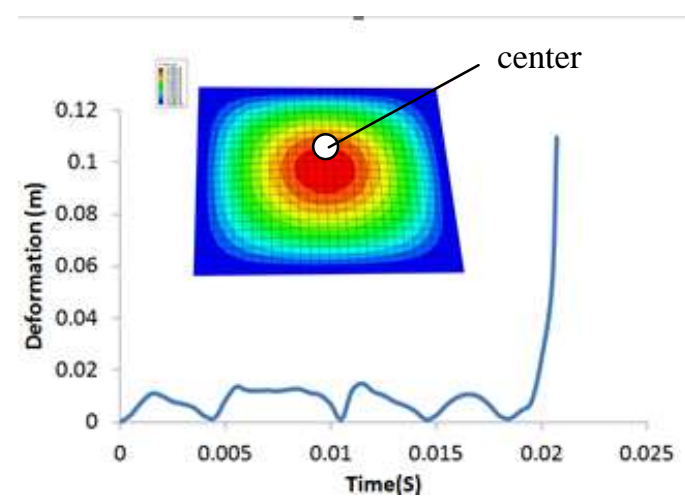

Figure 6- Permanent deformation at the center location of steel plate 


\section{The Dynamic Response of Skirt on ACV impacted by bubble}

\section{A. Model of simulation}

With the same above methods of simulating the damaged bubble dynamic. The same properties of air, water and bubble charge were used (TABLE 1), the new model of ACV was added. Figure.7 shows the position and the size of water, air and explosive charge model. The overall length of the hovercraft is $57 \mathrm{~m}$. The beam and draft of the hovercraft are $25.6 \mathrm{~m}$ and $1.6 \mathrm{~m}$, respectively is illustrated in Figure.8. The whole finite element model is shown in Figure.9. The stiffener, the keel are all box steel with the cross section and the specifications are lists in TABLE 2. The body structure was constructed by aluminum (7075 Alloy), modeled using the average thickness technique of the hovercraft was $20 \mathrm{~mm}$, meanwhile the thickness of skirt part is $2.5 \mathrm{~mm}$ and made by a few kinds of materials. In the fist model, ACV's skirt will make by rubber and in the second model of skirt, it will be checked the response with the coated fabric material [20].

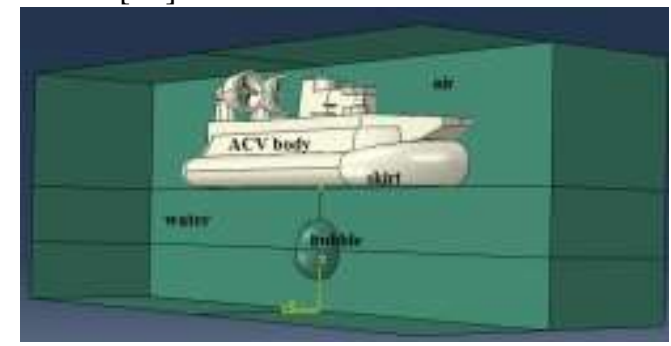

Figure 7. Set up model of ACV's skirt response

The mechanical properties of the hovercraft body and especially skirt properties are shown in TABLE 3.

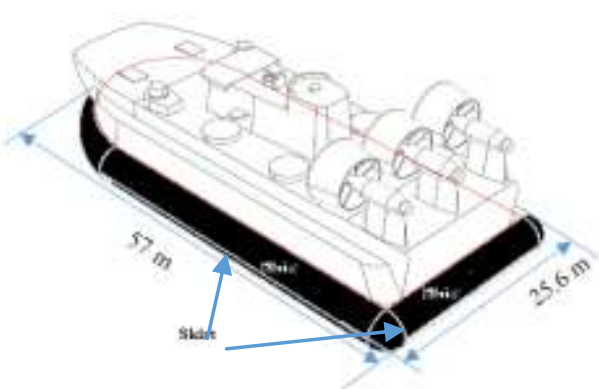

Figure 8. ACV' Skirt model

Figure.9 and Figure.10 show mesh of ACV model including skirt mesh. There are some types of elements in this model including linear quadrilateral elements of type S4R, shell elements, linear beam, line elements, and linear triangular of type S3 elements. The element size is $0.5 \mathrm{~m}$. It includes 380 cell faces, 1135 edges, and 792 vertices.

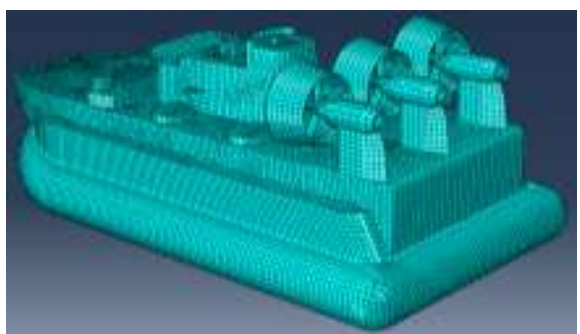

Figure 9. Finite element models of Zubr-class like LCAC

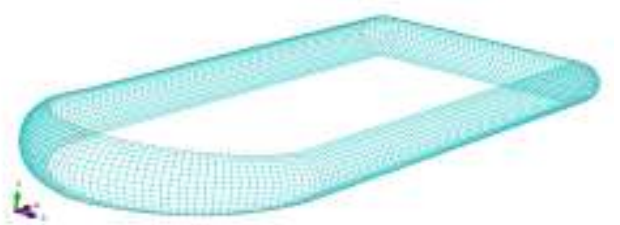

Figure 10. Mesh of skirt model

TABLE 2 shows the parameters of the fabric skirt structure. The properties of them also give in the TABLE 3.

TABLE 2. The parameters of fabric skirt [21]

\begin{tabular}{|l|l|l|}
\hline Skirt fabric designation & \multicolumn{1}{|c|}{ Units } & \multicolumn{1}{c|}{ Size } \\
\hline Width & $\mathrm{mm}$ & $830-840$ \\
\hline Thickness & $\mathrm{mm}$ & 2.5 \\
\hline Specific weight & $\mathrm{kg} / \mathrm{m}^{2}$ & 2.57 \\
\hline Tearing strength & $\mathrm{N}$ & 1490 \\
\hline
\end{tabular}

TABLE 3. Mechanical properties of body structure and skirt [21]

\begin{tabular}{|c|c|c|c|}
\hline $\begin{array}{c}\text { Parameters } \\
\text { (Units) }\end{array}$ & $\begin{array}{c}\text { Body } \\
\text { Structural }\end{array}$ & $\begin{array}{c}\text { Skirt } \\
\text { (fabric) }\end{array}$ & ( rubber) \\
\hline $\begin{array}{c}\text { Density } \\
\left(\mathrm{kg} / \mathrm{m}^{3}\right)\end{array}$ & 2780 & 2700 & 8060 \\
\hline $\begin{array}{c}\text { Young's } \\
\text { Modulus } \\
\text { (GPa) }\end{array}$ & 75.6 & 70 & 2.461 \\
\hline $\begin{array}{c}\text { Poisson's } \\
\text { ratio }\end{array}$ & 0.33 & 0.3 & 0.323 \\
\hline $\begin{array}{c}\text { Yielding } \\
\text { stress } \\
(\mathrm{MPa})\end{array}$ & 300 & - & - \\
\hline
\end{tabular}

For simplicity, the light footprint pressure 3000 $\mathrm{Pa}$ is adopted to describe the cushion pressure 
when the fan speed is increasing further, pressure remains almost constant [20](shows in Figure 11).

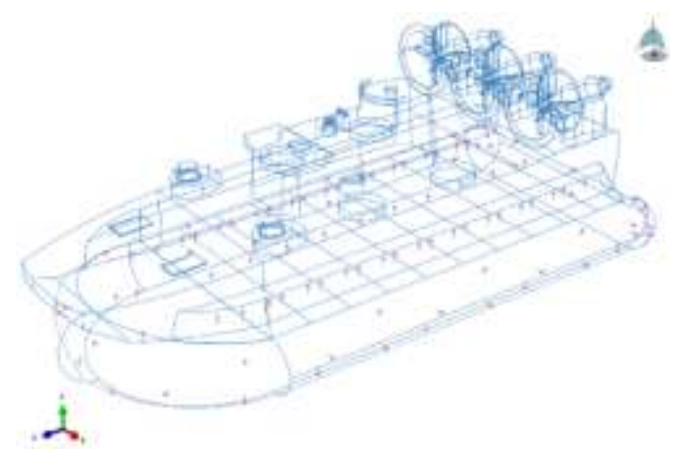

Figure 11. Footprint pressure for ACV [20]

\section{в. Dynamic response of Air Cushion Vehicle with bubble impact}

In this section, we apply the CEL method to the numerical study of the potential damage to a hovercraft's skirt subjected to UNDEX in the different kind of skirt materials: rubber and fabric. The numerical model involves a bubble produced by using $9 \mathrm{~kg}$ of TNT located under the middle of hovercraft model. The model includes three regions of material, water, air and highly compressed detonation gas. Figure. 12 shows a schematic of the numerical model. In the fluid model, the length is 100 meters, the width is 50 meters, and the height is 40 meters.

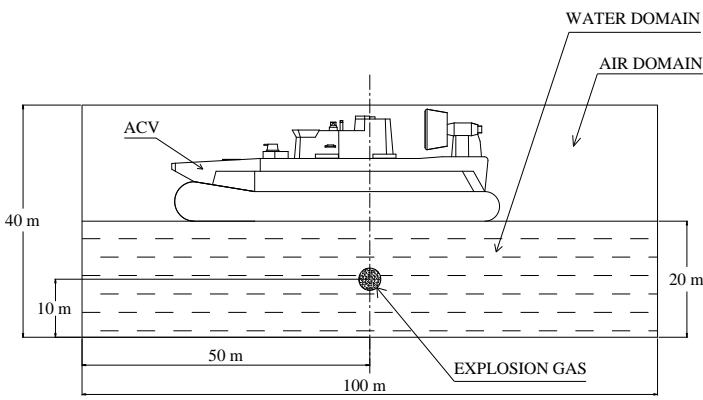

Figure 12. The arrangement of the model In this study, the near field underwater explosion was simulated which the explosive charge detonates close to the ship hull.

\section{Results and discussion}

\section{A. Rubber Skirt Response}

Dynamic responses of the ACV's rubber skirt model at typical times are showed as the Figure.13.

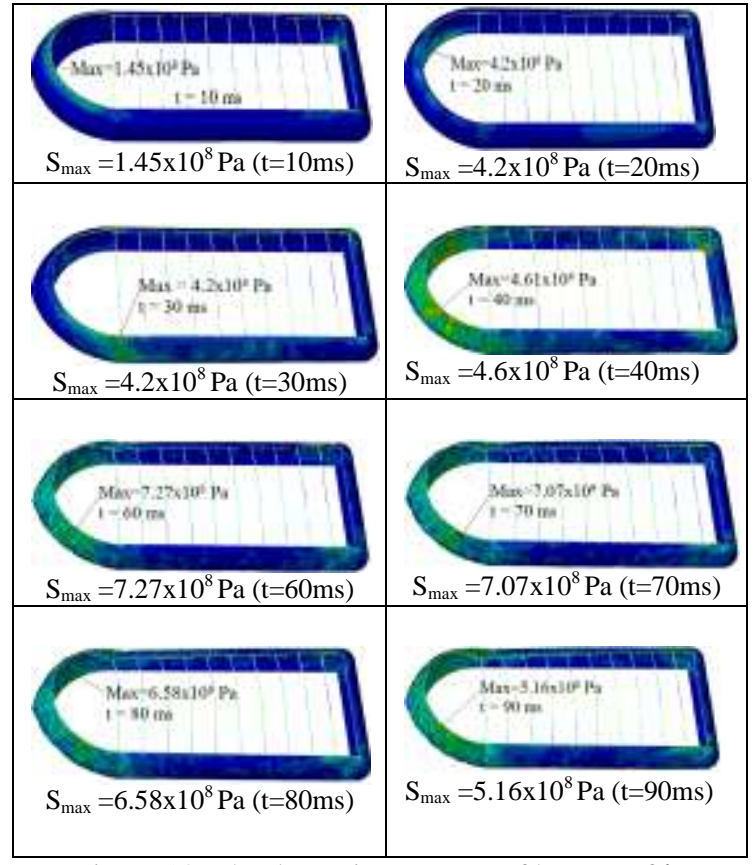

Figure 13. The dynamic response of hovercraft's rubber skirt model under the load of bubble pulse

It can clearly observed that the displacement of the hovercraft's skirt model subjected to bubble load is mainly the global response. At the time $\mathrm{t}=$ $10 \mathrm{~ms}$, the bubble pulse affect skirt in a small pressure, the shape of skirt from $\mathrm{t}=10 \mathrm{~ms}$ to $\mathrm{t}=$ $70 \mathrm{~ms}$ is likely stable. However, we are easy to recognize that at the time $\mathrm{t}=80 \mathrm{~ms}$ and $\mathrm{t}=90 \mathrm{~ms}$ the skirt is damaged considerably.

In the Figure.13, von Mises Stress followed the time were illustrated. It also included the maximum and minimum values at the specific position of the element and node. Base on this data source, we could determine the very dangerous area where will be damaged considerably. From the database, we are easy to see the maximum value is $4.600 \times 10^{8} \mathrm{~Pa}$ at the time $\mathrm{t}=40 \mathrm{~ms}$, the node $16013^{\text {th }}$, the $5^{\text {th }}$ element. At the same period of this time, the minimum value is $1.384 \times 10^{-6} \mathrm{~Pa}$ in the $1.219^{\text {th }}$ element, the $5^{\text {th }}$ node. It is noticeable at $\mathrm{t}=60 \mathrm{~ms}$, in the $1.14100^{\text {th }}$ element and the $3979^{\text {th }}$ node, the value of von Mises Stress peaked at 7.27 x $10^{8} \mathrm{~Pa}$.

\section{B. Fabric Skirt Response}

The Figure.14 shows the outcomes of impact of high-pressure bubble in UNDEX process to fabric skirt.

\section{Fabric skirt response}

Rubber skirt response 
Proc. of the Seventh International Conference On Advances in Civil and Structural Engineering - CSE 2017. Copyright $\odot$ Institute of Research Engineers and Doctors. All rights reserved.

ISBN: 978-1-63248-127-6 doi: 10.15224/ 978-1-63248-127-6-36

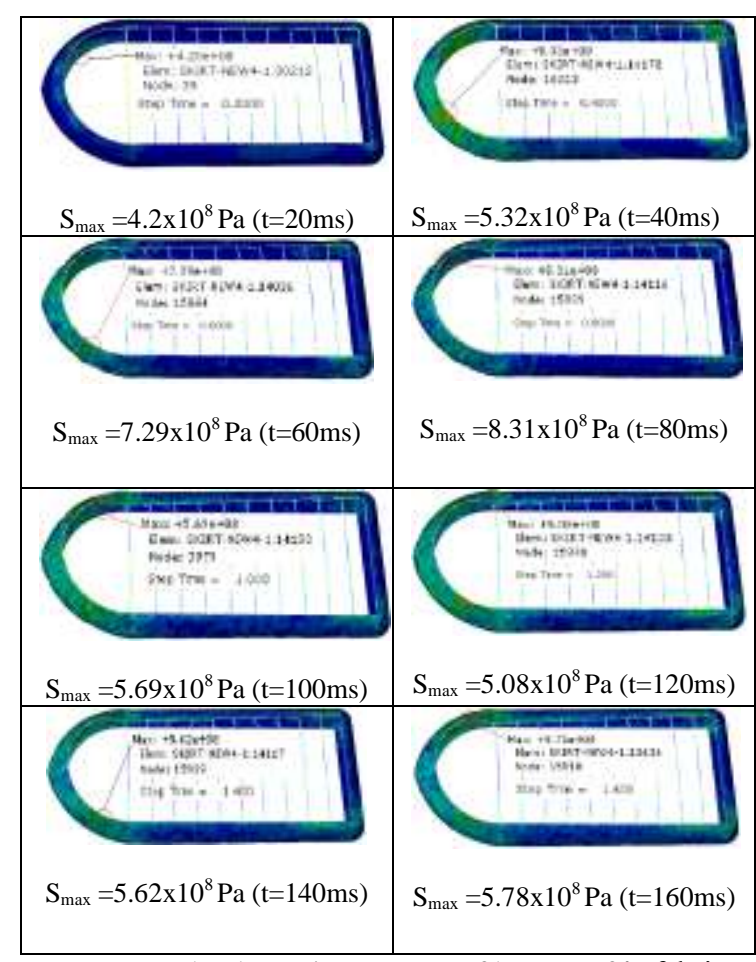

Figure 14. The dynamic response of hovercraft's fabric skirt model under the load of bubble pulse

The deformation of fabric skirt follow the different time is illustrated. The span of the time from $\mathrm{t}=20 \mathrm{~ms}$ to $60 \mathrm{~ms}$, the destroying of fabric skirt is smallish. It is noticeable at the period of time from $\mathrm{t}$ bigger $80 \mathrm{~ms}$. Especially, at $\mathrm{t}=100$ $\mathrm{ms}$ the fabric skirt is unprofitable. In the Figure.14, von Mises Stress followed the time were illustrated. It also included the maximum and minimum values at the specific position of the element and node. Base on this data source, we could determine the very dangerous area where will be damaged considerably.

From the database, we are easy to see the maximum value is $1.452 \times 10^{8} \mathrm{~Pa}$ at the time $\mathrm{t}=$ $20 \mathrm{~ms}$, the node $1557^{\text {th }}$, the $130024^{\text {th }}$ element.

At the same period of this time, the minimum value is $1.856 \times 10^{-6} \mathrm{~Pa}$ in the $1202^{\text {th }}$ element, the $5674^{\text {th }}$ node. It is noticeable at $\mathrm{t}=80 \mathrm{~ms}$, in the $1.13617^{\text {th }}$ element and the $15501^{\text {th }}$ node, the value of von Mises Stress peaked at $8.31 \times 10^{8} \mathrm{~Pa}$. The bottom value at this time is $1790 \times 10^{-6} \mathrm{~Pa}$ in the $1276^{\text {th }}$ element and the $5789^{\text {th }}$ node. The most dangerous area on the skirt is concentrated at the head location as the Figure.19. The deformation of skirt with the high-pressure bubble at $\mathrm{t}=100$ $\mathrm{ms}$ was illustrated by the several of colors as Figure.15. The red elements on the skirt gave the high von-mises stress value. It will decrease following the changes of color from dark red to dark blue. It is very simple to observe the high von-mises stress value area. In the Figure.15, the ACV's head is the most damaged location from UNDEX by the high-pressure bubble.

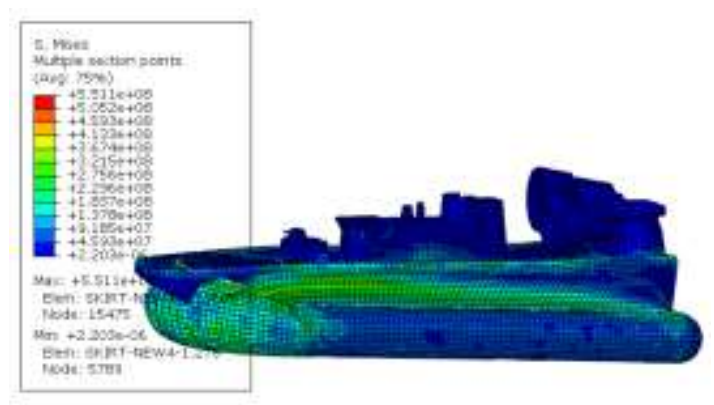

Figure 15. The deformation of skirt followed the changes of color

\section{Conclusions}

The purpose of this study is to investigate a procedure to analyze the dynamic structural response of a hovercraft. It shows the possibility of using the Coupled Eulerian- Lagrangian (CEL) method in ABAQUS. Numerical simulations were compared with the results of validated experimental data. The finite element simulation of the ACV's skirt model subjected to highpressure bubble simulation that were presented. The skirt response of the hovercraft model have been discussed. The consequences of simulated methodology could be an important reference to outline ACV's skirt structure. The calculated results excellently agree with experimental data, which indicates that the numerical model can effectively predict bubble pulse damage.

A numerical model of dynamics of an UNDEX bubble is developed using CEL method and Equation of State (EOS). Crucial effects of bubble on the structure were investigated, such as pressure pulse and water jet attack. The locations in the skirt and main deck sustain the significant effect on gas bubble behavior when a hovercraft damaged by UNDEX. Large global responses take place at the bubble load, followed by the formation of water jet. Bubble generated in underwater explosion has a significant impact on the general strength of hovercraft's skirt, even exceeding the effect of shock wave sometimes. The results show the importance of considering bubble pulsation in estimating the damage of structure induced by the UNDEX phenomenon. Through case studies, it is found that the high precision of the evaluation method. As a result, it can be applied to checking hovercraft's skirt overall capacity against underwater explosion ultimate damage. The analytical results were offering a reference for evaluating the damage of hovercraft's skirt structure under the underwater explosion which is very utility to forebode and 
Proc. of the Seventh International Conference On Advances in Civil and Structural Engineering - CSE 2017. Copyright $\odot$ Institute of Research Engineers and Doctors. All rights reserved.

ISBN: 978-1-63248-127-6 doi: 10.15224/ 978-1-63248-127-6-36

adopt a suitable material of skirt for designing a future hovercraft.

\section{Acknowledgements}

The authors gratefully acknowledged the financial support provided by Ministry of Science and Technology, Taiwan, ROC. (MOST 1032221-E-212-018-MB).

\section{References}

[1] E. Klaseboer, B. C. Khoo. "Dynamics of an oscillating bubble near a floating structur," Journal of Fluids and Structures, vol. 21 (2005), pp. 395-412. Received 25 August 2004; accepted 12 August 2005.

[2] A.M. Zhang, X.L. Yao, J. Li, "The interaction of an underwater explosion bubble and an elastic-plastic structure". Applied Ocean Research, vol. 30 (2008), pp. 159_171. Accepted 9 November 2008.

[3] Joon Chung, Tae-Cheol Jung. "Optimization of ai cushion vehicle bag and finger skirt using genetic algorithms". Aerospace Science and Technology, vol. 8 pp. 219-229, 2004

[4] Milton S. Plesset. "Bubble dynamics and cavitation". Annual Review of Fluid Mechanics, Vol.9, Department of Engineering Science, California Institute of Technology, Pasadena, California 91125, pp. 145 - 185, 1977.

[5] B. C. Nie, J. C. Li, H. Q. Zhang. "Interaction between reflected shock and bubble in near wall underwate explosion". Procedia Engineering, vol. 126, pp. 344348,2015 .

[6] Y. L. Zhang, K. S. Yeo,y B. C. Khoo, C. Wang. 3D Jet Impact and Toroidal Bubbles. Journal of Computational Physics, vol. 166, pp. 336-360, 2001.

[7] A. Pearson, E. Cox. "Bubble interactions near a free surface". Engineering Analysis with Boundary Elements, vol. 8, pp. 295-313, 2004.

[8] Q. X. Wang, K. S. YEO. Simulate the nonlinear evolution of gaseous bubbles in the vicinity of a free surfaces. PII: S0045- 7930(96)00007-2. Computer \& Fluid, vol. 25, No. 7, pp. 607-628, 1996.

[9] C. Wang, B. C. Khoo. Elastic mesh technique for 3D BIM simulation with an application to underwater explosion bubble dynamics. Computers \& Fluids, vol. 32, pp. 1195-1212. Received 15 March 2002; received in revised form 29 August 2002; accepted 2 October 2002.

[10] Jian Li, Ji-li Rong. The volume-acceleration model was introduced to determine the initial conditions for bubble motion during underwater explosions based on MSC.DYTRAN software. European Journal of Mechanics B/Fluids 2012; 32- 59-69, 2011.

[11] Jian Li, Ji-li Rong. Bubble and free surface dynamics in shallow underwater explosion. Ocean Engineering, vol. 38 (2011), pp. 1861-1868. Received 3 March 2010, Accepted 27 September 2011.

[12] Ching-Yu Hsu \& Cho-Chung Liang. A numerical study on the underwater explosion bubble pulsation and the collapse process. Ocean Engineering 81 (2014) 29-38. Accepted 19 February 2014, Available online 7 March 2014.

[13] G. Barras, M. Souli. Numerical simulation of underwater explosions using an ALE method \& the pulsating bubble phenomena. Ocean Engineering, Vol

\section{1, PP.53-66, Feb. 2012.}

[14] Jan Erik Olsen, Paal Skjetne. Modelling of underwater bubble plumes and gas dissolution with an EulerianLagrangian CFD model. Applied Ocean Research, Vol.59, PP.A3-200, Sep. 2016.

[15] Global Security.org, Zubr LCAC: http://www.globalsecurity.org/military/world/china/zub r.htm, 2016.

[16] Y. S. Shin. Naval ship shock design and analysis Report at government expense ME4525, 1994.

[17] ABAQUS Analysis User's Manual and Abaqus Theory Manual, version 6.11.1 Dassault Systèmes, RI, USA 2011.

[18] Kelvin H. Brown, Shawn P. Burns, Mark A. Christon. Coupled Eulerian- Lagrangian. Methods for Earth Penetrating Weapon Applications Sandia National Laboratories, Albuquerque, New Mexico 87185 and Livermore, California 94550, 2002.

[19] Robert H. Cole. Underwater explosion (book) Princeton, New Jersey- 1948. Princeton University Press.

[20] Liang Yun. Theory and Design of Air Cushion Craft. First published in Great Britain in 2000. Pages 232-272. Available online 12 October 2007

[21] Liang Yun Alan Bliault. Design and analysis of ACV and SES skirts. Theory \& Design of Air Cushion Craft, pp. 232-272, 2000.

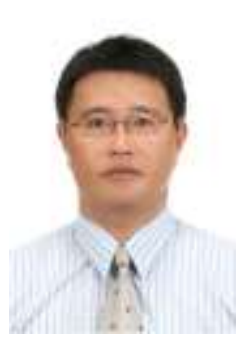

Ching-Yu Hsu was born in Taiwan. $\mathrm{He}$ is an Associate Professor in the Department of Marine Mechanical Engineering at the R.O.C. Naval Academic, Taiwan. He holds the Ph.D. in 2000 from the Chung Cheng Institute of Technology. His research interests include structure design, underwater shock and impact simulation and analysis of ships and submarine.

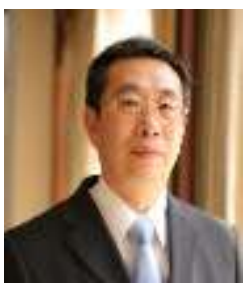

Cho-Chung Liang is currently working at Da-Yeh University, Changhua, Taiwan, R.O.C. as vice president. and chair professor in the department of Mechanical and Automation Engineering. He holds the Ph.D. in 1990 from National Tsing Hua University, Hsinchu, Taiwan, and the bachelor and the master of Naval Architecture in 1976 and in 1980 from National Defense University, Taoyuan, Taiwan, R.O.C. His research interests include shock and vibration, optimum design, vehicle crashworthiness and underwater explosion.

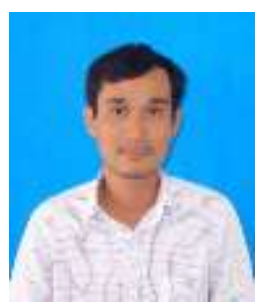

Phuong-Duy Vo comes from Vietnam,

he received the Master degree from the Vehicle Engineering at the University of Technical and Education (Ho Chi Minh city) in 2012. Currently, he is a Ph.D student from Automation and Technical Engineering Department at Dayeh University, Taiwan, ROC. His current interests: Underwater

Explosion, Numerical simulation, Engine Electronic. 
Proc. of the Seventh International Conference On Advances in Civil and Structural Engineering - CSE 2017. Copyright (C) Institute of Research Engineers and Doctors. All rights reserved.

ISBN: 978-1-63248-127-6 doi: 10.15224/ 978-1-63248-127-6-36

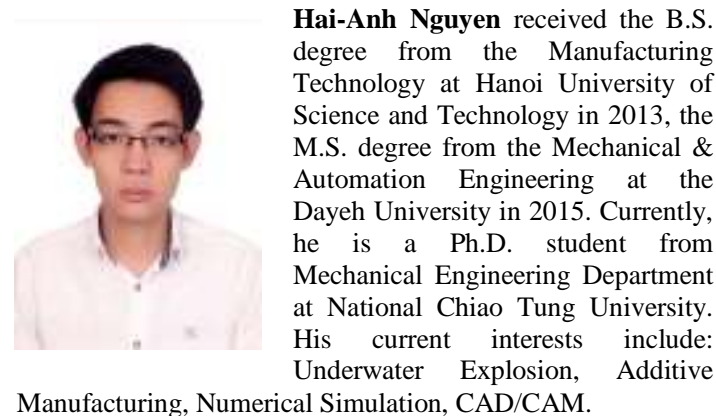

